\title{
Valor e predição do nível crítico de índices para avaliar o estado nitrogenado da batateira ${ }^{1}$
}

\author{
Value and prediction of critical content-level to assess the nitrogen status of the \\ potato
}

\author{
Fabrício Silva Coelho ${ }^{2 *}$, Paulo Cezar Rezende Fontes ${ }^{2}$, Paulo Roberto Cecon ${ }^{3}$, Heder Braun ${ }^{2}$ Ivo Ribeiro da \\ Silva ${ }^{4}$
}

\begin{abstract}
RESUMO - Independentemente do índice de nitrogênio (N) utilizado, a existência de valores aceitos como concentração crítica é necessária para uso como padrão de referência. Objetivou-se estabelecer níveis críticos do índice SPAD, ângulo Hue, concentração de $\mathrm{N}$-total e massa da matéria seca da quarta-folha da batateira por dois métodos e utilizar tais níveis críticos para a predição do estado de $\mathrm{N}$ da planta com base na produtividade relativa. Os experimentos foram conduzidos nas safras "de inverno" e "das águas". Os tratamentos foram constituídos por 5 doses de N aplicadas em pré-plantio $(0 ; 50 ; 100 ; 200$ e $300 \mathrm{~kg} \mathrm{ha}^{-1} \mathrm{de} \mathrm{N}$ ), na forma de uréia. O delineamento foi em blocos ao acaso com 4 repetições. A cultivar de batata utilizada foi a Ágata. Aos 21 dias após a emergência (DAE) foram determinados o índice SPAD, concentração de N-total, ângulo Hue e massa da matéria seca da quarta-folha a partir do ápice da batateira (MSQF). Para o cálculo do valor do nível crítico foram utilizados o procedimento gráfico de Cate-Nelson e matemático. Os erros da predição do diagnóstico do estado de N, a partir dos níveis críticos, foram estimados a partir do método gráfico de Cate-Nelson, quantificando-se a porcentagem de observações localizadas nos quadrantes negativos. Houve aparente discrepância no valor do nível crítico dos índices de $\mathrm{N}$ utilizando-se os dois procedimentos de cálculo. Os níveis críticos determinados aos 21 DAE são adequados para fazer avaliações relativamente precisas de suficiência de $\mathrm{N}$ em um estádio precoce de avaliação.
\end{abstract}

Palavras-chave: Diagnóstico. Nitrogênio. Prognóstico. Batata.

\begin{abstract}
Regardless of the nitrogen (N) content used, the existence of values, accepted as a critical concentration, is necessary for use as a reference standard. The objective was to establish critical levels of the SPAD index, Hue angle, concentration of total $\mathrm{N}$, and fourth-leaf dry matter of the potato plant, by two methods, and to use such critical levels for the prediction of the $\mathrm{N}$-status of the plant, based on the relative yield. The experiments were conducted on crops from the winter and rainy seasons. The treatments consisted of five dosages of $\mathrm{N}$, applied in the form of urea when planting $(0,50,100,200$ and $300 \mathrm{~kg} \mathrm{ha}^{-1}$ of $\mathrm{N}$ ). The design was of randomized blocks with four replications. The potato cultivar used was Agata. At 21 days after emergence (DAE) the SPAD index, concentration of total N, Hue angle and dry weight of the fourth leaf from the apex of the plant (MSQF), were all determined. To calculate the critical level, the Cate-Nelson graphical procedure and a mathematical procedure were used. The prediction errors of the diagnosis of the $\mathrm{N}$-status determined from the critical levels were estimated using the Cate-Nelson graphical method, by quantifying the percentage of observations which were located in negative quadrants. There was an apparent discrepancy in the critical-level values of $\mathrm{N}$ when using the two calculation procedures. The critical levels determined at $21 \mathrm{DAE}$ are suitable for making relatively accurate assessments of $\mathrm{N}$ sufficiency at an early stage of evaluation.
\end{abstract}

Key words: Diagnosis. Nitrogen. Prognosis. Potato.

\footnotetext{
*Autor para correspondência

${ }^{1}$ Recebido para publicação em 12/08/2011; aprovado em 10/06/2012

Parte da Tese de Doutorado do primeiro autor apresentada ao Programa de Pós-Graduação em Fitotecnia da Universidade Federal de Lavras; Pesquisa realizada com recursos financeiros do CNPq e da FAPEMIG

${ }^{2}$ Departamento de Fitotecnia, Universidade Federal de Viçosa/UFV, Viçosa-MG, Brasil, 36.570-000, fabriufla@yahoo.com.br; pacerefo@ufv.br; hederbraun@hotmail.com

${ }^{3}$ Departamento de Estatística, Universidade Federal de Viçosa/UFV, Viçosa-MG, Brasil, 36.570-000, cecon@ufv.br

${ }^{4}$ Departamento de Ciência do Solo, Universidade Federal de Viçosa/UFV, Viçosa-MG, Brasil, 36.570-000, ivosilva@ufv.br
} 


\section{INTRODUÇÃO}

O nitrogênio $(\mathrm{N})$ é essencial para o crescimento e desenvolvimento da cultura da batata (Solanum tuberosum L.) e tanto a deficiência quanto o excesso de $\mathrm{N}$ prejudica a produção comercial de tubérculos. No entanto, a utilização indiscriminada de fertilizantes está presente nas áreas de cultivos de batata e, em consequiência desse uso excessivo, ocorre o aumento do custo de produção, redução da qualidade dos tubérculos e risco da contaminação ambiental (BREGAGNOLI et al., 2003; ZVOMUYA et al., 2003).

Na recomendação da adubação nitrogenada para as condições brasileiras, alguns estados da região Sul e dos Cerrados têm utilizado o teor de matéria orgânica do solo como indicador da disponibilidade de N. No entanto, uma melhoria potencial seria a inclusão de características da planta que permitissemo monitoramento da disponibilidade de $\mathrm{N}$ durante o ciclo da cultura, visando maior precisão e flexibilidade no manejo do N. Para a batata, são citadas as análises em tempo real na planta envolvendo a utilização da tabela de cor (SILVA; FONTES, 2006), teor de nitrato no suco celular (MAJIC et al., 2009) e clorofilômetro SPAD-502 (COELHO et al., 2010; SILVA et al., 2011).

O medidor de clorofila Minolta SPAD-502 tem sido investigado como instrumento para rápido diagnóstico do estado nutricional de diversas culturas em relação ao conteúdo de N. O aparelho SPAD-502 possui dois LEDs (diodo emissor de luz) posicionados na extremidade do medidor, que emitem luz em sequência quando o medidor está fechado, na faixa do 600-700 nm (pico em $650 \mathrm{~nm}$ ), na qual a absorbância pela clorofila é alta, e na faixa de 860 a 1.060 (pico em $940 \mathrm{~nm}$ ), na qual a absorbância é baixa, funcionando como fator de correção em função da espessura da folha.

O colorímetro Minolta CR (séries 100; 200; 300 e 400), o qual fornece a informação a respeito do ângulo Hue $\left({ }^{\circ} \mathrm{h}\right)$, também pode ser uma ferramenta útil para a avaliação não destrutiva da coloração de tecidos vegetais, sendo que os valores de ${ }^{\circ} \mathrm{h}$ apresentam as seguintes correspondências quanto às cores da superfície do tecido vegetal: $0 \%$ vermelho, $90 \%$ amarelo, $180 \%$ verde e $270 \%$ azul. Portanto, o valor de ${ }^{\circ} \mathrm{h}$ do equipamento permite quantificar o teor de clorofilas em folhas, onde folha verde intensa, com elevado teor de clorofila, apresenta ${ }^{\circ} \mathrm{h}$ próximo de $180^{\circ}$, e folha clorótica, com baixo teor de clorofila, apresenta ${ }^{\circ} \mathrm{h}$ próximos de $90^{\circ}$ (AMARANTE et al., 2008).

Para ser útil em estratégias destinadas a decidir sobre a necessidade de adubação com $\mathrm{N}$, valores relativos dos índices de diagnóstico do estado de $\mathrm{N}$ da planta precisam ser comparados com os valores de níveis críticos (NC) da cultura. Tais níveis críticos podem ser conceituados como sendo os valores abaixo dos quais a produção pode ser limitada, devido a quantidade insuficiente de N (GOFFART et al., 2008). Para a batata, grande parte dos trabalhos encontrados na literatura utiliza a produtividade relativa da cultura para o cálculo do nível crítico (RODRIGUES, 2004).

O estabelecimento do NC e a sua avaliação podem ser uma informação útil para agricultores decidirem sobre a recomendação de $\mathrm{N}$ em suas lavouras. A forma tradicional de se obter níveis críticos passa por ensaio de calibração da produtividade vegetal em função do teor de um nutriente ou índice na planta. Segundo Walworth e Sumner (1988), muitos pesquisadores conduzem experimentos variando a dose do nutriente no solo, obtendo a produtividade e a concentração do nutriente no tecido vegetal. Essas concentrações são ajustadas em função das produtividades, utilizando-se modelos matemáticos, como Mitscherlich, quadrática, exponencial, entre outros. Em muitos casos, o nível crítico corresponde à concentração do nutriente associado a 90, 95 ou mesmo $99 \%$ da produtividade máxima. No entanto, o valor do nível crítico varia em função de diversos fatores entre os quais, genótipo, órgão analisado, idade da planta e da folha, modelo matemático utilizado para o cálculo, não sendo possível a utilização de um nível crítico universal.

Objetivou-se estabelecer níveis críticos do índice SPAD, ângulo Hue, concentração de N-total e massa da matéria seca da quarta-folha da batateira em duas épocas de cultivo pelo procedimento gráfico de Cate-Nelson e matemático e utilizar tais níveis críticos para a predição do estado de $\mathrm{N}$ da planta com base na produtividade relativa.

\section{MATERIAL E MÉTODOS}

Foram conduzidos dois experimentos na Horta de Pesquisa do Departamento de Fitotecnia (DFT) da Universidade Federal de Viçosa (UFV), no município de Viçosa, Minas Gerais (latitude: $20^{\circ} 45^{\prime} \mathrm{S}$; longitude $42^{\circ} 51^{\prime} \mathrm{W}$; altitude: $693 \mathrm{~m}$ ). O primeiro experimento foi conduzido no período de inverno ("safra de inverno"), de 27 de maio a 04 de setembro de 2010. O segundo experimento foi conduzido no período chuvoso ("safra das águas"), no período de 10 de novembro de 2010 a 11 de fevereiro de 2011, em área contígua àquela utilizada no primeiro experimento.

$\mathrm{O}$ solo em que foram instalados os experimentos foi classificado como Argissolo Vermelho-Amarelo câmbico (EMPRESA BRASILEIRA DE PESQUISA AGROPECUÁRIA, 2006) e a análise granulométrica da camada $0-20 \mathrm{~cm}$ revelou $51 \%$ de argila, $35 \%$ de areia e $14 \%$ de silte. Em relação à análise química, o solo apresentou 1,4\% de matéria orgânica e $3,5 \mathrm{cmol}_{c} \mathrm{dm}^{-3}$ de CTC 
a pH 7,0 na safra "de inverno" e 1,4\% de matéria orgânica e 4,2 $\mathrm{cmol}_{\mathrm{c}} \mathrm{dm}^{-3}$ de CTC a pH 7,0 na safra "das águas".

O delineamento experimental utilizado foi de blocos ao acaso, sendo os tratamentos constituídos de 5 doses de $\mathrm{N}\left(0 ; 50 ; 100 ; 200\right.$ e $300 \mathrm{~kg} \mathrm{ha}^{-1}$ de $\left.\mathrm{N}\right)$ aplicadas no sulco, em pré-plantio, com 4 repetições. Como fonte de $\mathrm{N}$ foi utilizada a uréia $(44 \%$ de $\mathrm{N})$.

Cada parcela foi constituída de duas fileiras com doze plantas cada, com espaçamento de $0,75 \mathrm{~m}$ entre fileiras e 0,25 m entre plantas, e dimensões de 3,0 m de comprimento e 1,0 m de largura. Consideraram-se como bordaduras as duas plantas das extremidades das fileiras, restando 20 plantas úteis por parcela.

Aos 45 dias antes da instalação dos experimentos foi realizada a calagem com o objetivo de elevar a saturação por bases para $60 \%$ (FONTES, 2005). Para isso, foram aplicadas 2,5 e 2,4 t ha ${ }^{-1}$ de calcário dolomítico PRNT 76\% nos experimentos "de inverno" e "das águas", respectivamente. A adubação foi feita manualmente no sulco de plantio e consistiu de $1.800 \mathrm{~kg} \mathrm{ha}^{-1}$ de superfosfato simples $\left(18 \%\right.$ de $\left.\mathrm{P}_{2} \mathrm{O}_{5}\right), 384 \mathrm{~kg} \mathrm{ha}^{-1}$ de cloreto de potássio (60\% de $\mathrm{K}_{2} \mathrm{O}$ ), $200 \mathrm{~kg} \mathrm{ha}^{-1}$ de sulfato de magnésio (10\% de $\mathrm{Mg}), 10 \mathrm{~kg} \mathrm{ha}^{-1}$ de bórax (10\% de B), $10 \mathrm{~kg} \mathrm{ha}^{-1}$ de sulfato de zinco (20\% de $\mathrm{Zn}), 10 \mathrm{~kg} \mathrm{ha}^{-1}$ de sulfato de cobre $(24 \%$ de $\mathrm{Cu}$ ) e $0,5 \mathrm{~kg} \mathrm{ha}^{-1}$ de molibdato de sódio (39\% de Mo). A uréia e os demais adubos foram aplicados no sulco e misturados, sendo feito o plantio logo em seguida. Além disso, foi feita a aplicação do inseticida carbofuran.

A cultivar utilizada foi a Ágata. O plantio foi realizado utilizando-se tubérculos de batata-semente certificada, com massa média de $70 \mathrm{~g}$, previamente brotada, com broto de aproximadamente $3 \mathrm{~cm}$. Não houve tratamento para quebra de dormência dos tubérculos. A amontoa foi realizada aos 22 dias após a emergência das plantas.

As irrigações foram por aspersão convencional, no período da manhã, com lâmina de água estabelecida a partir da estimativa da evapotranspiração de referência e do coeficiente de cultura (Kc). A estimativa de evapotranspiração de referência foi realizada pelo método de Penman-Monteith mantendo-se o solo com umidade próxima à capacidade de campo (ALLEN, 1993).

Aos 21 dias após a emergência (DAE), período em que o produtor normalmente realiza as adubações em cobertura, três plantas foram amostradas aleatoriamente para a realização das leituras do Índice de Cor Verde com o medidor portátil SPAD-502 (Soil-PlantAnalysis Development-502, Konica Minolta, Japão). A medição foi feita no folíolo terminal da quarta folha completamente expandida a partir do ápice da planta (QF), entre 8:00 e 11:00 horas da manhã. Nestas mesmas folhas foram realizadas as leituras com o colorímetro portátil Colortec-
PCM (Konica Minolta, Japão), para a determinação do ângulo Hue $\left({ }^{\circ} \mathrm{h}\right)$. Posteriormente, as folhas $(\mathrm{QF})$ foram destacadas da planta e colocadas em estufa a $65^{\circ} \mathrm{C}$, até atingirem massa constante, para a obtenção da massa da matéria seca. Essa foi triturada em moinho tipo Wiley para determinação das concentrações de $\mathrm{N}$-orgânico $\left(\mathrm{N}-\mathrm{NH}_{4}^{+}\right) \mathrm{e}$ $\mathrm{N}$-nitrato $\left(\mathrm{N}^{-} \mathrm{NO}_{3}^{-}\right)$, de acordo com metodologia proposta por Silva (2003). A concentração de $\mathrm{N}$-total foi calculada pela soma das concentrações de $\mathrm{N}$-orgânico $\left(\mathrm{N}-\mathrm{NH}_{4}^{+}\right)$e $\mathrm{N}$-nitrato $\left(\mathrm{N}^{-\mathrm{NO}_{3}^{-}}{ }_{3}\right.$ )determinadas em laboratório.

A partir dos valores de nível crítico das variáveis analisadas na QFe da produtividade relativa determinada nas safras "de inverno" e das "águas", foram analisadas as relações existentes entre essas duas características de acordo com os procedimentos estabelecidos por CateNelson (1987) e modificados por Fox et al. (2001). Para tal, os valores de nível crítico estimados para cada índice de avaliação do estado de $\mathrm{N}$ da planta (índice SPAD, ângulo Hue, concentração de N-total e massa da matéria seca da quarta-folha) foram plotados no eixo $\mathrm{X}$ e a produtividade relativa no eixo Y. Considerou-se como $98 \%$ do rendimento relativo o nível crítico obtido com a linha traçada do eixo horizontal. Este valor foi escolhido baseando-se em trabalhos de Coelho et al. (2010) e Fontes et al. (2010), em que as produtividades estimadas com a dose de máxima eficiência econômica ficaram em torno de $98 \%$ da máxima produtividade física de tubérculos de batata.

Os valores de nível crítico plotados no eixo $\mathrm{X}$ foram utilizados em conjunto com o valor crítico do eixo Y para definir os erros ou "outliers". Assim, de acordo com a análise gráfica, os dados que se encontram no quadrante superior esquerdo contêm os erros ou "outliers" dos tratamentos que superestimaram a necessidade de $\mathrm{N}$, ou seja, mostraram que as plantas do tratamento eram deficientes em $\mathrm{N}$, mas que, na verdade, havia $\mathrm{N}$ suficiente para atingir o rendimento máximo. Já os dados que se encontram no quadrante inferior direito contêm os erros dos tratamentos que subestimaram a necessidade de $\mathrm{N}$, ou seja, indicaram que as plantas do tratamento não eram deficientes em N, mas, de fato, haveria a necessidade de se aplicar mais $\mathrm{N}$ para atingir o rendimento máximo. As observações que ficaram plotadas nos quadrantes superior esquerdo e no quadrante inferior direito foram consideradas como sendo os erros, pois os valores dos índices do estado de $\mathrm{N}$ observados ficaram abaixo do nível crítico estimado e apresentaram produtividade relativa superior a $98 \%$ ou, os valores dos índices ficaram acima do nível crítico e apresentaram produtividade relativa abaixo de $98 \%$.

Pelo método gráfico de Cate-Nelson e a partir das equações de regressão estimadas pela relação entre produtividade relativa e índice SPAD, ângulo Hue, concentração de N-total e massa da matéria seca 
da quarta-folha, foram calculados os níveis críticos utilizando-se 100; 99; 98; 95 e 90\% da produtividade comercial relativa.

A partir das doses de $252 \mathrm{~kg} \mathrm{ha}^{-1}$ e $279 \mathrm{~kg} \mathrm{ha}^{-1}$ de $\mathrm{N}$, as quais proporcionaram as produtividades de máxima eficiência econômica nas safras "de inverno" e "das águas", respectivamente (COELHO, 2011), estimaram-se níveis críticos associados a 100; 99; 98; 95 e $90 \%$ dessas respectivas doses. Para tal, as doses de 252; 249,5; 247; 239,4 e 226,8 $\mathrm{kg} \mathrm{ha}^{-1} \mathrm{~N}$, na safra "de inverno" foram substituídas nas equações de regressão das variáveis em função de doses de N. Para a safra "das águas" as doses utilizadas foram 279; 276,2; 273,$4 ; 265$ e $251,1 \mathrm{~kg} \mathrm{ha}^{-1}$ de $\mathrm{N}$.

\section{RESULTADOS E DISCUSSÃO}

Os valores da relação entre o índice SPAD e a produtividade relativa são apresentados na Figura 1. Pela análise gráfica proposta por Cate-Nelson, verifica-se que a utilização dos níveis críticos estimados 45,4 e 46,5 resultou em erros de 30 e $10 \%$ nas safras "de inverno" e "das águas", respectivamente. Esses erros correspondem aos valores dos índices do estado de $\mathrm{N}$ observados que ficaram abaixo do nível crítico estimado e apresentaram produtividade relativa superior a 98\%; ou ainda, os valores dos índices que ficaram acima do nível crítico e apresentaram produtividade relativa abaixo de $98 \%$. Valores críticos do índice SPAD variando de 35,2 a 53,0, determinados aos $21 \mathrm{DAE}$, foram verificados na cultura da batata na região de Viçosa em outras condições experimentais, épocas de plantio e cultivares (FONTES et al., 2010; SILVA et al., 2009; COELHO et al., 2010).
Pela análise proposta por Cate-Nelson para o ângulo Hue, verifica-se que a utilização dos níveis críticos estimados de 119,6 na safra "de inverno" e 115 na safra "das águas" resultou em erros de 25 e 15\%, respectivamente (Figura 2).

Para a concentração de $\mathrm{N}$-total na quarta folha (QF), a utilização dos níveis críticos estimados de 53,6 na safra "de inverno" e 46,3 na safra "das águas" resultou em erros de 50 e $5 \%$, respectivamente (Figura 3), de acordo com a análise proposta por Cate-Nelson. Valores de 40 a $65 \mathrm{~g} \mathrm{~kg}^{-1}$ de $\mathrm{N}$ na matéria seca da folha completamente desenvolvida da batateira jovem (entre 15 e 45 DAE) são citados como adequados (RODRIGUES, 2004).

Os valores da relação entre a massa da matéria seca da quarta folha (MSQF) e a produtividade relativa são apresentados na Figura 4. Pela análise gráfica proposta por Cate-Nelson verifica-se que a utilização dos níveis críticos estimados 745,4 e 632,7 mg resultou em erros de 10 e $15 \%$ nas safras "de inverno" e "das águas", respectivamente.

Analisando os erros dos níveis críticos do índice SPAD, ângulo Hue, concentração de N-total e MSQF verifica-se que, com exceção da MSQF, todos os demais erros foram menores na safra "das águas" em comparação à safra "de inverno". Uma possível explicação para os menores erros encontradas na safra "das águas" pode ser o menor teor de $\mathrm{N}$ no solo na época das chuvas, ocasionado por perda de $\mathrm{N}^{-} \mathrm{NO}^{-}{ }_{3}$ por lixiviação, principalmente na fase anterior à emergência da planta (DYNIA et al., 2006), facilitando assim o diagnóstico do estado de $\mathrm{N}$ da planta.

Os vários modelos que expressam a relação entre dose de $\mathrm{N}$ e a produção da planta ou o índice determinado na folha são variáveis e complexos, podendo gerar valores discrepantes de nível crítico. Além disso, os fatores que proporcionarem mudanças

Figura 1 - Análise gráfica de Cate-Nelson da relação entre os valores de nível crítico SPAD e a produtividade relativa de tubérculos na colheita nas safras "de inverno" (A) e "das águas" (B)
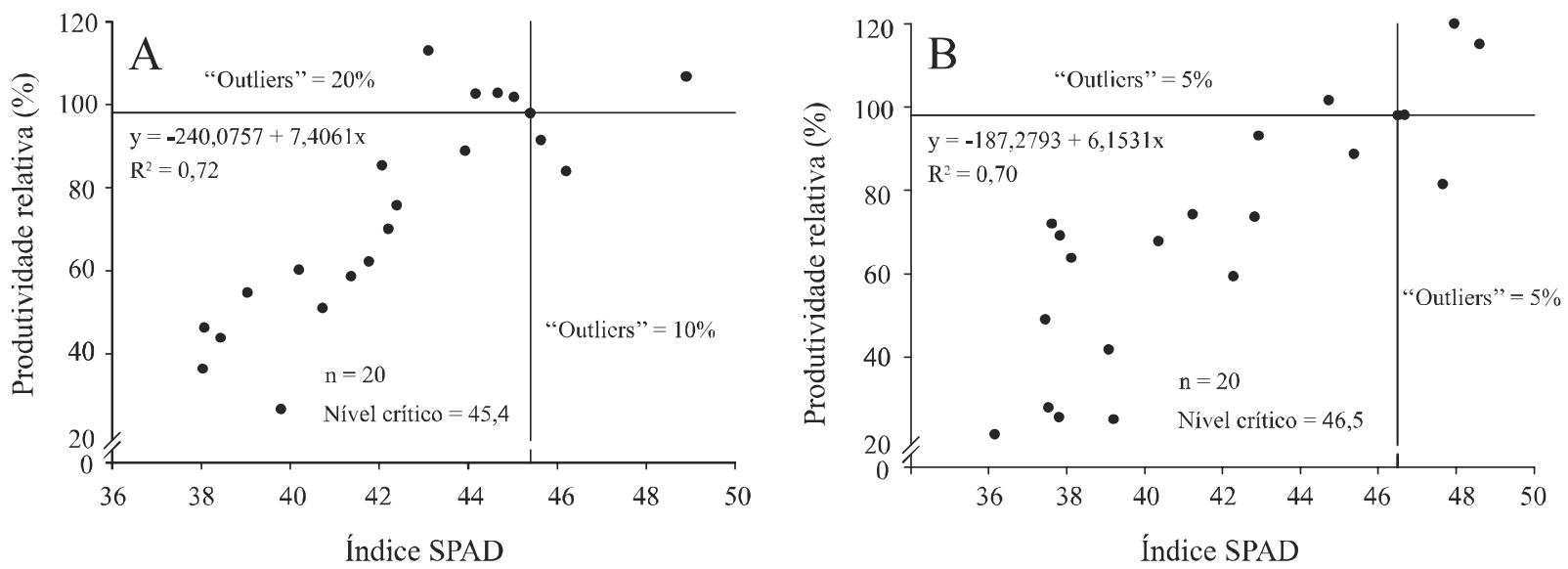
diferenciadas na taxa de crescimento e na absorção do $\mathrm{N}$ favorecerão diferenças nas concentrações do nutriente no tecido, provocando mudanças do nível considerado como crítico (FONTES, 2011).

Figura 2 - Análise gráfica de Cate-Nelson da relação entre os valores de nível crítico do ângulo Hue e a produtividade relativa de tubérculos na colheita nas safras "de inverno" (A) e "das águas" (B)
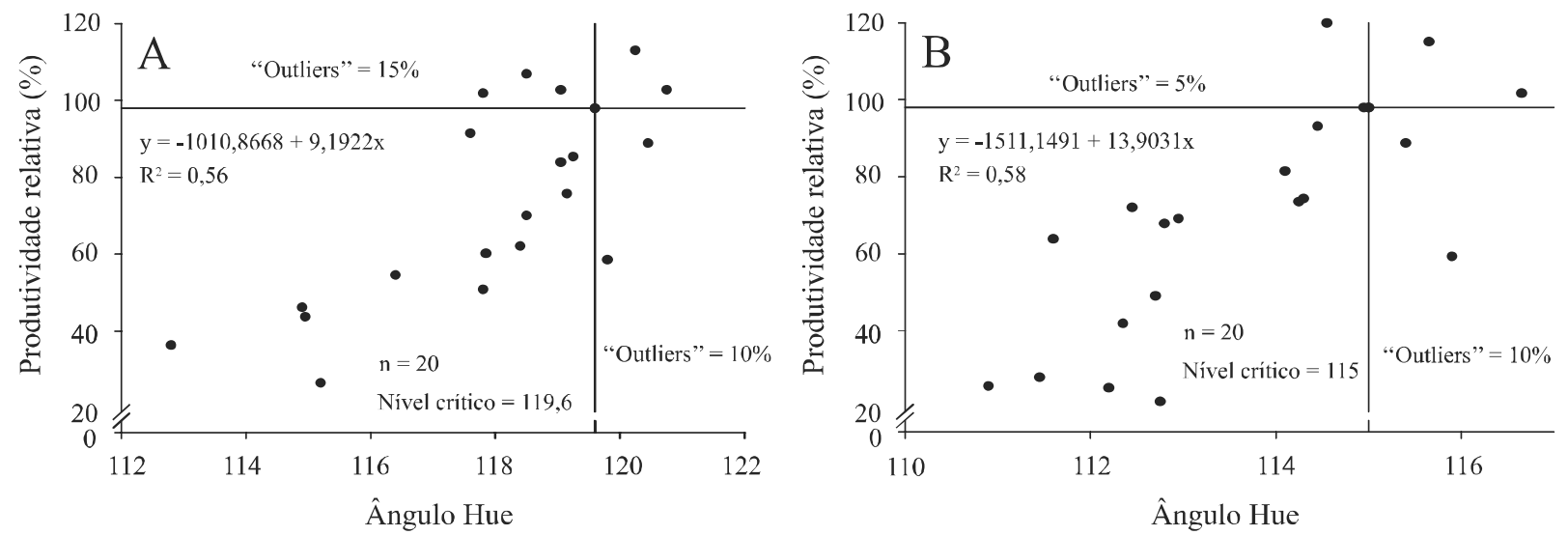

Figura 3 - Análise gráfica de Cate-Nelson da relação entre os valores de nível crítico da concentração de N-total e a produtividade relativa de tubérculos na colheita nas safras "de inverno" (A) e "das águas" (B)
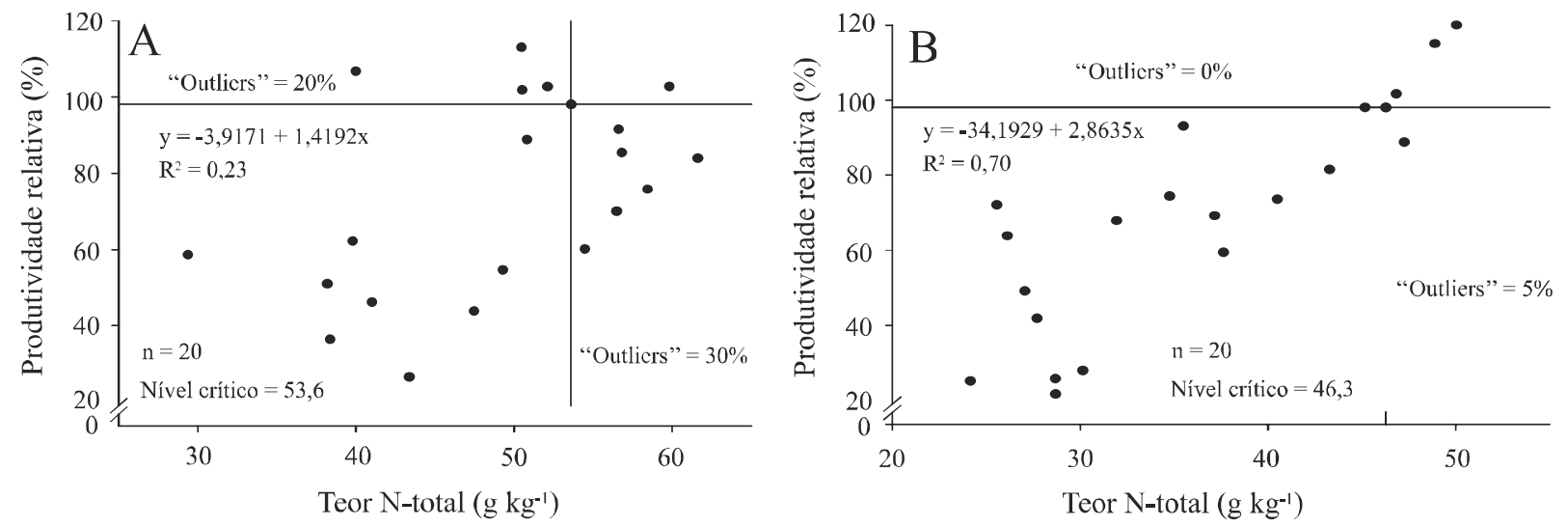

Figura 4 - Análise gráfica de Cate-Nelson da relação entre os valores de nível crítico da massa da matéria seca da quarta-folha (MSQF) da batata e a produtividade relativa de tubérculos na colheita nas safras "de inverno" (A) e "das águas" (B)
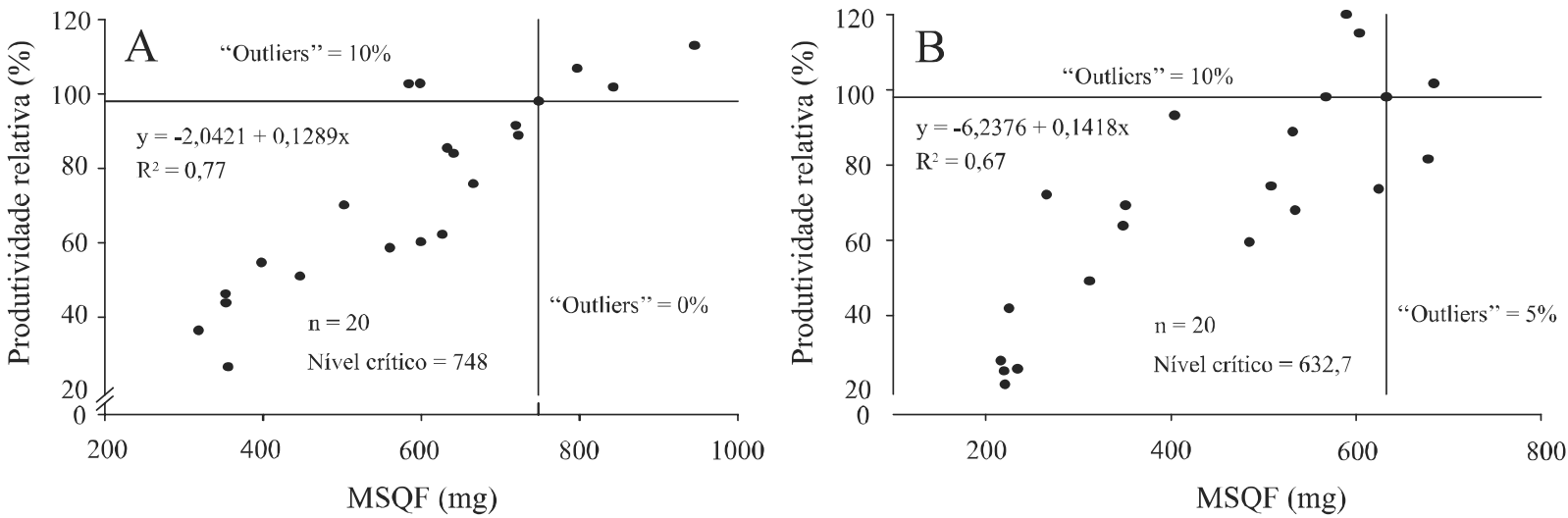
Os "outliers" (erros) associados aos níveis críticos correspondem às falhas no diagnóstico (a falta da adubação ou sua aplicação desnecessária) e foram usados para comparar a acurácia relativa de indicadores para a diagnose da necessidade de complementação com N. Para a safra "de inverno" verificou-se que a percentagem de observações que ficaram no quadrante inferior direito do gráfico, indicando que o tratamento era deficiente em $\mathrm{N}$, mas de fato, haveria a necessidade de se aplicar mais $\mathrm{N}$ para atingir o rendimento máximo, indicando erros, foi de $10 \%$ para o índice SPAD, $10 \%$ para o ângulo Hue, $30 \%$ para a concentração de N e $0 \%$ para a MSQF. Para a safra "das águas", as percentagens de observações que ficaram no quadrante inferior direito do gráfico foram $5 ; 10 ; 5$ e $10 \%$ para o índice SPAD, ângulo Hue, concentração de N-total e MSQF, respectivamente.

Para um método ser aceitável pelos agricultores, a probabilidade do teste prever a suficiência de $\mathrm{N}$ quando na verdade a planta encontra-se deficiente, deve ser baixa (FOX et al., 2001). No presente estudo, dos índices de diagnósticos analisados, o nível crítico de $53,6 \mathrm{~g} \mathrm{~kg}^{-1}$ para a concentração de $\mathrm{N}$ na matéria seca da quarta-folha na safra "de inverno" não foi o índice mais apropriado para separar as plantas deficientes das não deficientes. Nesse caso, houve 30\% de falso-negativo, ou seja, 30\% dos tratamentos apresentaram-se acima do nível crítico, mas, no entanto, haveria a necessidade de aplicar mais $\mathrm{N}$ para atingir $98 \%$ do rendimento máximo. Neste sentido, o nível crítico mais adequado foi obtido com a massa da matéria seca da quarta-folha, não sendo verificado nenhum tratamento que subestimou a necessidade de $\mathrm{N}$ na "safra de inverno" e a concentração de N-total para a safra "das águas", apresentando erro de 5\%. Rodrigues (2004), trabalhando com seis doses de $\mathrm{N}$ em pré-plantio (0 a $300 \mathrm{~kg} \mathrm{ha}^{-1}$ ) na forma de uréia na cultura da batata, verificou que, pela metodologia gráfica de Cate-Nelson, houve erro de $25 \%$ ao utilizar o nível crítico da concentração de $\mathrm{N}$ na folha; para o índice SPAD o erro foi de $12,5 \%$ e para o teor de nitrato no suco celular foi $16,7 \%$, determinados aos 20 DAE. Ainda segundo o autor, a acurácia dos métodos de diagnose não melhorou durante o ciclo da cultura (10 aos 48 DAE), podendo a diagnose ser realizada precocemente, possibilitando realizar a complementação com $\mathrm{N}$ enquanto a demanda do nutriente pelas plantas é alta.

No entanto, Vos e Bom (1993) citam que o uso do clorofilômetro em estádio precoce do crescimento da batata, geralmente, fornece resultados inconsistentes não sendo possível estabelecer relações satisfatórias entre a intensidade do verde da folha e a produtividade. Segundo Cadahía e Lucena (2000), quando se comparam os métodos de diagnóstico nutricional, conclui-se que os métodos bioquímicos apresentam excessiva variabilidade, devido à pequena quantidade de material analisada, enquanto que os métodos visuais e de análise foliar apresentam pouca variabilidade, pois nestes casos as amostras obtidas são mais representativas.

Os níveis críticos estimados pelo método gráfico de Cate-Nelson e associados à dose de máxima eficiência econômica em várias percentagens da produtividade relativa e da dose de máxima eficiência econômica, nas safras "de inverno" e "das águas", são apresentados nas Tabelas 1 e 2, respectivamente. Na safra "de inverno", o nível crítico do índice SPAD associado a $99 \%\left(\mathrm{CV}_{99}\right)$ da produtividade relativa e da dose de máxima eficiência econômica, variou de 45,8 a 45,3 para o método gráfico e de máxima eficiência econômica (MEE), respectivamente (Tabela 1). Os valores correspondentes na safra "das águas" foram de 46,5 a 46,4 (Tabela 2). O nível crítico da concentração de N-total na QF para $\mathrm{CV}_{99}$ estimados pelo método gráfico e de $\mathrm{MEE}$ variaram

Tabela 1 - Valores críticos do índice SPAD, ângulo Hue, concentraçãode N-total ( $\left.\mathrm{g} \mathrm{kg}^{-1}\right)$ e massa da matéria seca (MSQF, em mg), estimados pelo gráfico de Cate-Nelson (NC gráfico) e pela associação da dose de máxima eficiência econômica (NC MEE), em diferentes percentagens da produtividade relativa e da dose de máxima eficiência econômica, na safra "de inverno"

\begin{tabular}{lcrrrrr}
\hline \multirow{2}{*}{ Característica } & \multirow{2}{*}{ Método } & \multicolumn{5}{c}{ Percentagem do máximo (\%) } \\
\cline { 2 - 6 } & & 100 & 99 & 98 & 95 & 90 \\
\hline \multirow{2}{*}{ SPAD } & Gráfico & 45,9 & 45,8 & 45,6 & 45,2 & 44,6 \\
\multirow{2}{*}{ Ângulo Hue } & MEE & 45,4 & 45,3 & 45,2 & 45,0 & 44,7 \\
& Gráfico & 120,8 & 120,7 & 120,6 & 120,3 & 119,8 \\
\multirow{2}{*}{ N-total } & MEE & 120,0 & 120,0 & 120,0 & 120,0 & 120,0 \\
& Gráfico & 67,7 & 67,0 & 66,3 & 64,2 & 60,7 \\
\multirow{2}{*}{ MSQF } & MEE & 53,6 & 53,6 & 53,6 & 53,6 & 53,6 \\
& Gráfico & 791,6 & 783,9 & 776,1 & 752,8 & 714,1 \\
& MEE & 745,4 & 744,9 & 744,4 & 742,4 & 737,7 \\
\hline
\end{tabular}


Tabela 2 - Valores críticos do índice SPAD, ângulo Hue, concentraçãode $\mathrm{N}$-total $\left(\mathrm{g} \mathrm{kg}^{-1}\right)$ e massa da matéria seca (MSQF, em mg), estimados pelo gráfico de Cate-Nelson (NC gráfico) e pela associação da dose de máxima eficiência econômica (NC MEE), em diferentes percentagens da produtividade relativa e da dose de máxima eficiência econômica, na safra "das águas"

\begin{tabular}{lcrrrrr}
\hline \multirow{2}{*}{ Característica } & \multirow{2}{*}{ Método } & \multicolumn{5}{c}{ Percentagem do máximo (\%) } \\
\cline { 2 - 6 } & & 100 & 99 & 98 & 95 & 90 \\
\hline \multirow{2}{*}{ SPAD } & Gráfico & 46,7 & 46,5 & 46,4 & 45,9 & 45,1 \\
& MEE & 46,5 & 46,4 & 46,3 & 46,1 & 45,6 \\
\multirow{2}{*}{ Ângulo hue } & Gráfico & 115,9 & 115,8 & 115,7 & 115,5 & 115,2 \\
& MEE & 115,0 & 115,0 & 115,0 & 115,0 & 115,0 \\
\multirow{2}{*}{ N-total } & Gráfico & 46,9 & 46,5 & 46,2 & 45,1 & 43,4 \\
\multirow{2}{*}{ MSQF } & MEE & 46,3 & 46,1 & 45,9 & 45,3 & 44,3 \\
& Gráfico & 647,5 & 640,6 & 633,7 & 613,0 & 578,5 \\
& MEE & 632,7 & 628,9 & 625,1 & 613,7 & 594,8 \\
\hline
\end{tabular}

de 67 a 53,6 $\mathrm{g} \mathrm{kg}^{-1}$ na safra “de inverno" e 46,5 a 46,1 $\mathrm{g} \mathrm{kg}^{-1}$ na "safra das águas".

A estimativa do valor do nível crítico de cada variável pelo método gráfico na safra “de inverno" forneceu valor aparentemente superior do que o correspondente nível crítico estimado com base na dose de máxima eficiência econômica, não ocorrendo o mesmo na safra "das águas" (Tabela 1). Essa aparente discrepância de valores entre os dois procedimentos para estimar o nível crítico, pode ser atribuída à maior sensibilidade do método matemático em relação à dispersão dos pontos e à dificuldade dos modelos curvilineares em ajustar os dados separando as regiões de suficiência e deficiência de $\mathrm{N}$. Além disso, o fato do cálculo do nível crítico pelo procedimento gráfico ter sido feito utilizando os valores de cada repetição, aliado ao fato de ter-se assumido a maior produtividade relativa como sendo aquela associada à dose de máxima eficiência econômica, pode ter contribuído para esta aparente discrepância.

Ao comparar valores de níveis críticos, deve-se levar em consideração a forma pela qual os mesmos foram determinados (BLACK, 1993). Fontes e Ronchi (2002) verificaram na cultura do tomate, que o valor do nível crítico determinado para o índice SPAD, teor de nitrato no suco celular e concentração de $\mathrm{N}$ na folha variaram de acordo com o procedimento estatístico para as determinações dos referidos níveis.

Conceitualmente, há tempos, o nível crítico vem sendo definido como o índice ou a concentração do nutriente com a qual a planta terá $10 \%$ de redução na sua máxima produtividade física. No entanto, para Fontes (2011) há situações em que a redução de $10 \%$ na produção máxima é inaceitável, devido ao valor comercial da cultura em relação ao custo do fertilizante. Assim, pelo fato da batata ser responsiva à adição de $\mathrm{N}$, pela relatividade de preços de batata/adubo e pelos dados observados neste trabalho, é plausível trabalhar com nível crítico associado a $98 \%$ da produtividade física. A escolha do procedimento a ser utilizado para a estimativa do valor do nível crítico deve ser baseada em critérios para a escolha do modelo estatístico que descreve a relação entre a dose do nutriente e o índice de diagnóstico. Dentre esses critérios deve-se considerar a lógica biológica do fenômeno, significância do quadrado médio da regressão, alto valor do coeficiente de determinação e significância dos parâmetros da regressão (ALVAREZ, 1994). Além destes critérios, é preciso considerar que o valor do nível crítico deve ser aquele em que, acima do qual, não há aumento na produção econômica.

\section{CONCLUSÕES}

1.Houve aparente discrepância no valor do nível crítico (NC) dos índices de $\mathrm{N}$ estimados pelo procedimento gráfico de Cate-Nelson e pelo procedimento matemático, com valores menores para o último. Assim, visando diminuir o uso excessivo de $\mathrm{N}$, o método matemático pode ser utilizado como um procedimento mais conservador para as recomendações das adubações em cobertura;

2. Apesar de não ter sido verificado menores erros do nível crítico do índice SPAD nas safras das "águas" e de "inverno", este pode ser recomendado para avaliar o estado nitrogenado da batateira devido à facilidade de operação e por fornecer leituras relativas precisas;

3. Os resultados demonstraram que os níveis críticos determinados aos 21 dias após a emergência são adequados para fazer avaliações precisas de suficiência de $\mathrm{N}$ em um estágio precoce de avaliação. 


\section{AGRADECIMENTOS}

Ao Conselho Nacional de Desenvolvimento Científico e Tecnológico ( $\mathrm{CNPq}$ ) pela concessão da bolsa de doutorado ao primeiro autor e a Fundação de Amparo à Pesquisa do Estado de Minas Gerais (FAPEMIG) e CNPq pelo auxílio financeiro.

\section{REFERÊNCIAS}

ALLEN, R. G. New approaches to estimating crop evapotranspiration. Acta Horticulturae, v. 335, p. 287-293, 1993.

ALVAREZ V. H. Avaliação da fertilidade do solo (Superfície de resposta modelos aproximativos para expressar a relação fator resposta). Viçosa: UFV, 1994. $75 \mathrm{p}$.

AMARANTE, C. V. T. et al. Quantificação não destrutiva de clorofilas em folhas através de método colorimétrico. Horticultura Brasileira, v. 26, n. 04, p. 471-475, 2008.

BLACK, C.A. Soil Fertility Evaluation and Control. Boca Raton: Lewis Publishers, 1993.746 p.

BREGAGNOLI, M. et al. Análise bromatológica de sete cultivares de batata (Solanumtuberosum L.) cultivadas na safra de verão no Sul de Minas Gerais. Horticultura Brasileira, v. 21, p. 387-387, 2003.

CADAHÍA, C.; LUCENA, J. J. Diagnostico de nutrición y recomendaciones de abonado. In: CADAHÍA, C. Fertirrigación: cultivos hortícolas y ornamentales. 2. ed. Madrid: Ediciones Mundi-Prensa, 2000. p. 173-246.

CATE, R. B.; NELSON, L. A. A simple statistical procedure for partitioning soil test correlation data in two classes. Soil Science Society of America Proceedings, v. 35, p. 658-660, 1987.

COELHO, F. S. etal. Dose de nitrogênio associada à produtividade de batata e índices do estado de nitrogênio na folha. Revista Brasileira de Ciência do Solo, v. 34, p. 1175-1183, 2010.

COELHO, F. S. Uso do clorofilômetro como ferramenta de manejo da adubação nitrogenada da cultura da batata. 2011. 162 f. Tese (Doutorado em Fitotecnia) - Universidade Federal de Viçosa, Minas Gerais, 2011.

DYNIA, J. F. et al. Lixiviação de nitrato em latossolo cultivado com milho após aplicações sucessivas de lodo de esgoto. Pesquisa Agropecuária Brasileira, v. 41, n. 05, p. 885-862, 2006.

EMPRESABRASILEIRADEPESQUISAAGROPECUÁRIA. Centro Nacional de Pesquisa de Solos. Sistema brasileiro de classificação de solo. 2. ed. Rio de Janeiro: Embrapa Solos, 2006. 306 p.
FONTES, P. C. R.; RONCHI, C. P. Critical values of nitrogen indices in tomato plants grown in soil and nutrient solution determined by different statistical procedures. Pesquisa Agropecuária Brasileira, v. 37, n. 10, p. 1421-1429, 2002.

FONTES, P. C. R. Olericultura: teoria e prática. Viçosa: Editora UFV, 2005. 486p.

FONTES, P. C. R. et al. Economic optium nitrogen fertilization rates and nitrogen fertilization rate effects on tuber characteristics of potato cultivars. Potato Research, v. 53, n. 03, p. 167-179, 2010.

FONTES, P. C. R. Nutrição mineral de plantas: avaliação e diagnose. Viçosa, MG: Arka Editora, 2011. 296 p.

FOX, R. H. et al. Comparison of late-season diagnostic tests for predicting nitrogen status of corn. Agronomy Journal, v. 93, n. 03, 590-597, 2001.

GOFFART, J. P. et al. Potato crop nitrogen status assessment to improve $\mathrm{N}$ fertilization management and efficiency: past-presentfuture. Potato Research, v. 51, n. 03/04, p. 355-383, 2008.

MAJIC, A. et al. Nitrate-nitrogen rates in petiole sap of potato crop (Solanum tuberosum L.). Acta Horticulturae, v. 846, p. 333-338, 2009.

RODRIGUES, M. A. Establishment of continuous critical levels for indices of plant and presidedress soil nitrogen status in the potato crop. Communications in Soil Science and Plant Analysis, v. 35, n. 13/14, p. 2067-2085, 2004.

SILVA, F. C. Manual de análises químicas de solos, plantas e fertilizantes. Brasília: EMBRAPA, 2003. 627 p.

SILVA, M. C. C.; FONTES, P. C. R. Proposição de uma tabela de cor (UFV 80-Monalisa) para a avaliação do estado de nitrogênio da batateira. Revista Batata Show, ano 6, n. 16, 2006.

SILVA, M. C. C. et al. Índice SPAD e produção de batata, em duas épocas de plantio, em função de doses de nitrogênio. Horticultura Brasileira, v. 27, p. 17-22, 2009.

SILVA, M. C. C. et al. Índice SPAD em função de diferentes horários e posições no folíolo da batata sob fertilização nitrogenada. Revista Ciência Agronômica, v. 42, n. 04, p. 971-977, 2011.

VOS, J.; BOM, M. Hand-held chlorophyll meter: a promising tool to assess the nitrogen status of potato foliage. Potato Research, v. 36, n. 04, p. 301-308, 1993.

WALWORTH, J. L.; SUMNER, M. E. Foliar diagnosis: a review. Advances in Plant Nutrition, v. 03, p. 193-24, 1988.

ZVOMUYA, F et al. Nitrate leaching and nitrogen recovery following application of polyolefin-coated urea of potato. Journal of Environmental Quality, v. 32, n. 02, p. 480-489, 2003. 